Haya: The Saudi Journal of Life Sciences

Abbreviated Key Title: Haya Saudi J Life Sci

ISSN 2415-623X (Print) |ISSN 2415-6221 (Online)

Scholars Middle East Publishers, Dubai, United Arab Emirates

Journal homepage: https://saudijournals.com/sjls

Original Research Article

\title{
Prevalence of Sub Clinical Mastitis in Large Animals with Antimicrobial Study
}

Dr. R. P. Diwakar ${ }^{1 *}$, Dr. Rajesh Kumar², Dr. Sanjay Kumar ${ }^{3}$, Dr. Safayat Husain ${ }^{4}$, Dr. Jitendra Kumar ${ }^{5}$

${ }^{1}$ Assistant Prof., Department of Veterinary Microbiology, College of Veterinary Science \& Animal Husbandry, Achary Narendra Deva University of
Agriculture \& Technology, Kumarganj, Ayodhya (UP)-224229, India
${ }^{2}$ Assistant Professor, Department of Veterinary Gyne. \& Obst., College of Veterinary Science \& Animal Husbandry, Achary Narendra Deva University
of Agriculture \& Technology, Kumarganj, Ayodhya (UP)-224229, India
${ }^{3}$ Professor, Department of LMP, College of Veterinary \& Animal Sciences, G.B.P.U.A\&T, Pantnagar, (UK), India
${ }^{4}$ PG Scholar, Department of Veterinary Gyne. \& Obst., College of Veterinary Science \& Animal Husbandry, Achary Narendra Deva University of
Agriculture \& Technology, Kumarganj, Ayodhya (UP)-224229, India ${ }^{5} \mathrm{PhD}$ Scholar, Department of Veterinary Gyne. \& Obst., College of Veterinary Science \& Animal Husbandry Jabalpur, NDVSU Jabalpur (MP), India

DOI: $10.36348 /$ sjls.2020.v05i09.001 $\quad$ | Received: 18.08 .2020 | Accepted: 26.08 .2020 | Published: 17.09 .2020

*Corresponding author: Dr. R. P. Diwakar

\section{Abstract}

In this Study, takes 219 milk samples (110 from cows and 109 from buffaloes) were screened for mastitis first with California mastitis Test (CMT) and risen cultural sensitivity test (CST) was performed on alt the positive samples from different villages of Banda Districts of Utter Pradesh in different seasons of the year. Data was analysed and overall animal season wise prevalence of mastitis was observed. Higher prevalence was observed in winter season in cows $(27.52 \%)$ and in rainy season in buffaloes $(33.94 \%)$ followed by winter season in cows and buffalos respectively. Antibiogram study was also done on all the samples and Enrofloxacin was found to be most sensitive antibiotic followed by Gentamicin and Ceftriaxone.

Keywords: Antibiotic sensitivity, bovines and mastitis seasons.

Copyright @ 2020: This is an open-access article distributed under the terms of the Creative Commons Attribution license which permits unrestricted use, distribution, and reproduction in any medium for non-commercial use (NonCommercial, or CC-BY-NC) provided the original author and source are credited.

\section{INTRODUCTION}

India has highest number of cattle population in world and stands first in milk production. It possesses the best genetic resources of buffaloes in the world. Mastitis is a big emerging problems in global and one of the most important diseases of economic importance affecting dairy sectors in India and worldwide. More than 155 bacterial species, subspecies and serovariants have been isolated from affected mammary glands of different species that associated with mastitis. Mastitis affects the both, quality and quantity of milk. In India, an annual loss due to mastitis in cows and buffaloes has been calculated to the tone of Rs.7 165.51 crores of which $57.93 \%$ losses are due to sub clinical mastitis. Higher productive dairy animals over the period of time and its positive correlation with mastitis incidence makes that treatment of mastitis during lactation is an inevitable tool, and thus it is an important part of economic losses in mastitis affected dairy animals. However, "successful treatment" of all mastitis cases remains the challenging task for veterinarians across the globe. Complex nature of disease caused very little progress in understanding the reasons for low cure rate. In our study, we studied season wise prevalence of sub clinical mastitis in large animals the seasons were classified as winter (December to March), summer (April to June), rainy (July to September), and autumn (October to November) and inter out some conclusion that how season affect onset of mastitis its prevalence, its progression and how we should manage it after receiving a concrete data followed by antimicrobial study on causative agents too for better formulation of treatment regime and to create better stately to prevent this huge loss.

\section{MATERIALS AND METHODS}

The present investigation on sub clinical mastitis was carried out in cows and buffaloes by conducting California mastitis test (CMT) and cultural sensitivity test (CST) of the milk samples received in Department of Veterinary Microbiology laboratory, College of Veterinary Science and Animal Husbandry, Narendra Deva University of Agriculture and Technology, Kumarganj. Faizabad (India). 


\section{Source of milk samples}

A total of 219 milk samples (110 from cows and 109 from buffaloes) were received at Department of Veterinary Microbiology laboratory, College of Veterinary Science and Animal Husbandry, Narendra Deva University of Agriculture and Technology, Kumarganj, Faizabad (India), for mastitis were first screened with CMT and then with CST on all the positive samples. Farmers were advised to collect milk samples under aseptic conditions. The udders of cows and buffaloes were cleaned thoroughly with a cloth containing dilute potassium permanganate.

The first few milk stripping were discarded and nearly I $0-15 \mathrm{ml}$ of quarter milk sample was collected separately in sterilized test tubes. These test tubes were marked as right fore (RF). right hind ( $\mathrm{RH})$, left fore (LF) and left hind (LH) .

\section{Prevalence}

California mastitis test (CMT): The CMT reagent is detergent based, that reacts with cellular content and inflammatory substance in milk to form a viscous gel or precipitation. The rest was performed as per Doxy [1] with CMT reagent solution: 3gm of sodium lauryl sulfate was added to $100 \mathrm{ml}$ distilled water and mixed thoroughly. The solution was heated at $50^{\circ} \mathrm{C}$ in a water bath to make it clear. Bromocresol purple was added to the solution to make the final concentration as I: 10000 and $\mathrm{pH}$ adjusted to 8 .

Equal quantities of milk sample and the reagent solution $(2-3 \mathrm{ml}$ were mixed in a plastic plate having four cups, representing each milk quarter as RF. $\mathrm{RH}, \mathrm{LF}$ and LH. The plate was rotated gently with the help of a handle, in a circular fashion for 20 seconds. The positive result was shown by the development of a viscous gel that tended to swirl towards the centre.

\section{Bacteriological examination}

The milk samples were streaked on nutrient agar with the help of a $4 \mathrm{~mm}$ diameter platinum loop.
The plates were incubated aerobically at $37^{\circ} \mathrm{C}$ for 24 to 48 hours. Sub-cultures the isolated organism in MacConkev's lactose agar (MLA) plates for find the pure colonies of bacteria and identified on the basis of grams reaction, morpholopy and colony characteristics (Fig-1).

\section{Drug Sensitivity Pattern}

Different strains of various organisms isolated from udder infections were subjected to in-vitro drug sensitivity testing, using nine antimicrobials by discdiffusion method as described by Bauer and coworkers [2]. The sensitivity was observed on the basis of zone size interpretation chart, provided by the manufacturer. The results were recorded as sensitive, intermediate and resistant.

\section{RESULTS}

In this Study a total of 219 milk samples (110 from cows and 109 from buffaloes) were screened for sub clinical mastitis first viz. CMT and then CST were performed on all the samples. Data was analyzed and overall animal season wise prevalence of mastitis was observed. Prevalence in winter season was $(27.52 \%)$ cows and $(33.94 \%)$ in buffaloes in rainy season (Table$1)$. Higher prevalence was observed in winter season in cows $(27.52 \%)$ and in rainy season in buffaloes $(33.94 \%)$. As data found in my research study that is, in subclinical mastitis cases in cattles more frequently found in winter season $(30,27.52 \%)$ followed by rainy and summer season at same percentage $(25,22.72 \%)$ in each season and less commonly seen in spring seasons $(10,9.09 \%)$, while in case of buffaloes sub clinical mastitis cases occur in the rainy season $(37,33.94 \%)$ followed by winter season $(27,24.77 \%)$ then in summer season $(24,22.01 \%)$ and least cases found in the spring season $(20,24.77 \%)$. Overall scenario for occurrence of sub clinical mastitis throughout a year is, rainy season winter season - summer season - spring season.

Table-1: Seasonal cases of mastitis in buffaloes and cows

\begin{tabular}{|l|l|l|l|l|l|l|}
\hline Species & & Rain & Spring & Winter & Summer & Total \\
\hline Cattle & Positive & $25(22.72 \%)$ & $10(9.09 \%)$ & $30(27.52 \%)$ & $25(22.93 \%)$ & $90(77.27 \%)$ \\
\hline & Negative & 04 & 03 & 07 & 06 & 20 \\
\hline & Total & 29 & 13 & 37 & 31 & 110 \\
\hline Buffalo & Positive & $37(33.94 \%)$ & $20(24.77 \%)$ & $27(24.77 \%)$ & $24(22.01 \%)$ & $108(99.08 \%)$ \\
\hline & Negative & 0 & 01 & 0 & 0 & 01 \\
\hline & Total & 37 & 21 & 27 & 24 & 109 \\
\hline Overall & Positive & $62(31.31 \%)$ & $30(15.15 \%)$ & $57(28.78 \%)$ & $49(24.74 \%)$ & $198(90.41 \%)$ \\
\hline & Negative & 04 & 04 & 07 & 06 & 21 \\
\hline & Total Examine & 66 & 34 & 64 & 55 & 219 \\
\hline
\end{tabular}

\section{DISCUSSION}

The season variation is an important factor that directly affects the occurrence of mastitis [3, 4]. The present study revealed that high incidence of mastitis was recorded winter season in cows and rainy season in buffaloes, which is in agreement with Shinde and coworkers [5]. Jadhav and coworkers [6] and Ameh and coworkers [7]. The high percentage of humidity in both the seasons may cause the most growth of pathogenic agents. Some deficiencies such as selenium and 
vitamine- E deficiency result in an increased incidence of clinical mastitis and dietary supplementation improves udder health with the effects most evident at calving and early lactation [8]. In USA Olde Riekerink and coworkers [9] showed the increase in the somatic cell count (SCC) during the cold seasons who established the highest proportion of clinical mastitis during the winter. According to the authors, the incidence of clinical mastitis caused by environmental or infectious pathogens are largely dependent on the production system. In farms where cattle grazed on pastures. The typical environmental coli mastitis exhibited a peak during the winter. Other studies reported a summer increase (from June to August) of clinical streptococcal species and E. coli mastitis in farms with rearing installs all the year round [10]. Taking into consideration the specific epidemiology of each pathogen, the relationship between disease prevalence and climatic/ecological factors could be various. During the summer, the humidity and high ambient temperatures are responsible for the development of coli forms in the bedding [11] whereas for cows grazing in the summer these problems are more frequent during the winter period [12]. In summer, immunosuppression because of heat stress (THI in summer > 72) may also have a role for higher occurrence rate of clinical mastitis in cows during late lactation. Olde Riekerink and coworker's [9] said that clinical mastitis happened more in the summer in case of cow compared to the winter. The mastitis cows in spring and winter had lower days in milk after calving compared to that of cows in summer during early Lactation period. Ghavi Hossein-Zadeh and and coworkers 17 reported that of clinical mastitis increased in multiporous cows (odds ratio, OR - 2.53), in winter seasons $(\mathrm{OR}=1.6 \mathrm{~S})$ and in the first month of lactation $\mathrm{OR}=3.3 \mathrm{~S}$. The present and preceding studies indicate that the risk of developing mastitis in monsoon and summer season is more as the conditions are favorable for the proliferation of pathogenic bacteria, due to adequate humidity and temperature of bacterial.

\section{Antibiotics Sensitivity Test}

Antibiotic sensitivity was performed on all the 219 samples, a total of 09 antibiotics were used Amikacine, Amphicillin, Ceftriaxone, ciprofloxacine, Enrofloxacine, gentamicine, cefoperazone, chloramphenicol and tetracycline (Table-2, Fig-2). Enrofloxacine is found to be a most suitable antibiotics followed by gentamicine $(90.41 \%)$ and Ceftriaxone $(81.27 \%)$ and least sensitive to tetracycline antibiotics. Rajan and others also found Enrofloxacine is a most sensitive antibiotic, whereas they observed lower sensitivity towards Ceftriaxone (84.10). Diwakar and others also found similar result 100 per cent sensitivity to Cloxacillin, Ceftriaxone and cefoperazone and high sensitivity towards Enrofloxacine, Cephalexin, Gentamicin and Lincomycine. The antibiotics obtained in current study indicated high sensitivity towards newer and older antibiotics showing rationale use of these antibiotics at field level.

Table-2: Antibiotics Sensitivity Test of CMT positive Milk samples

\begin{tabular}{|l|l|l|l|l|l|l|l|l|l|}
\hline Total & Amikacine & Amphicillin & Ceftriaxone & Ciprofoxacin & Enrofloxacine & Gentamicin & cefoperazone & $\begin{array}{l}\text { Chloram } \\
\text { phinicoi }\end{array}$ & Tetracycline \\
\hline 219 & 165 & 163 & 178 & 155 & 204 & 198 & 78 & 186 & 110 \\
\hline$\%$ & 75.34 & 74.42 & 81.27 & 70.77 & 93.15 & 90.41 & 35.61 & 84.93 & 50.22 \\
\hline
\end{tabular}

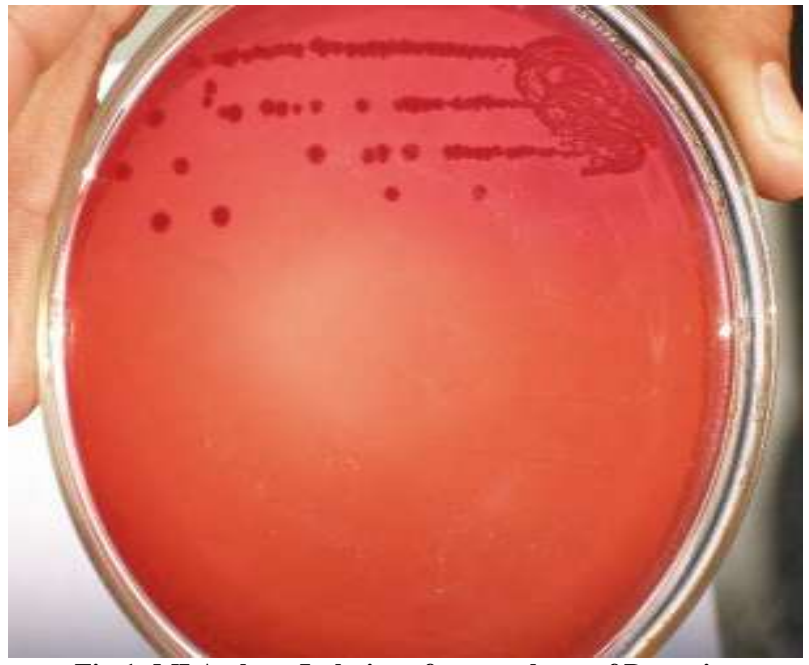

Fig-1: MLA plate: Isolation of pure culture of Bacteria

\section{CONCLUSION}

The above study carried on 219 milk samples (110 from cows and 109 from buffaloes) were screened for mastitis first with catifornia mastitis Test (CMT)

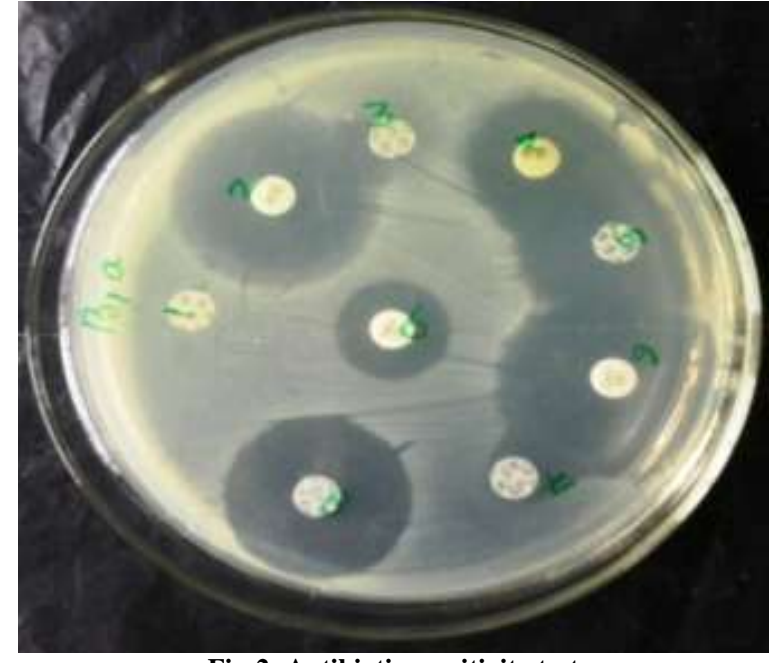

Fig-2: Antibiotic sensitivity test

and risen cultural sensitivity test (CST) was performed on all the positive samples in laboratory. Data was analysed and overall animal season wise prevalence of mastitis was observed. Higher prevalence was observed 
in winter season in cows $(27.52 \%)$ and in rainy season in buffaloes (33.94\%). Antibiotic sensitivity was performed on all the samples, Enrofloxacine is found to be a most suitable antibiotics followed by Gentamicine $(90.41 \%)$ and Ceftriaxone $(81.27 \%)$ and least sensitive to tetracycline antibiotics. Antibiogram study help in proper recommendation of antibiotics for early and timely treatment.

\section{FUTURE RESEARCH}

In Future, to isolate the all the bacteria which is involve in causation of mastitis and then one by one study the antibiogram of all the isolated bacteria according to this practice not injected the broad spectrum antibiotics, only uses the selective antibiotics which help the accurate treatment of suffering animals and also help the animal owner for save the money.

\section{REFERENCES}

1. Doxy, C. L. (1985). Clinical Pathology and Diagnostic Procedure. IInd Edn. Bailliare Tindal, London.

2. Bauer, A. W., Kirby, W. W. M. Sherris, J. C., \& Turch, M. (1996). Antibiotic susceptibility testing by a standardized single disc method. Am I clin Pathol. 45:493.

3. Johnson, H. D., \& Vanjonack, W. J. (1976). Effects of environmental and other stressors on blood hormone patterns in lactating animals. I of dairy sci. 59(9):1603-1617.

4. 8Shathele, M. S. (2009). Weather effect on bacterial mastitis in dairy cows. Inter I of Dairy Sci. 4(2):57-66.

5. Shinde, S. S., Kulkami, G. B. Gangane, G. K., \& Degloorkar, N. M. (2001). Incidence of mastitis in prebhani district of Maharashtra. Proceedings of the Round Table Conference on Mastitis, Ludhiana, India.

6. Jadhav, K., Tripathi, V. N., \& Kale, M. M. (1995). Incidence and economics and mammary disorders in holstein $\mathrm{X}$ sahiwal cross bred cows. Ind I of dairy Sci. 48:382-385.

7. Ameh, J. (1999). Prevalence of bovine mastitis in Maiduguri Borno State, Nigeria James Agbo Ameh*, Tobias Edgbe-Nwiyi, and Lamido Tanko Zaria. Veterinarski arhiv, 69(2), 87-95.

8. Weiss, W. P., Hogan, J. S., Smith, K. L., \& Hoblet, K. H. (1990). Relationships among selenium, vitamin E, and mammary gland health in commercial dairy herds. Journal of dairy science, 73(2), 381-390.

9. Riekerink, R. O., Barkema, H. W., \& Stryhn, H. (2007). The effect of season on somatic cell count and the incidence of clinical mastitis. Journal of dairy science, 90(4), 1704-1715.

10. Makovec, J. A., \& Ruegg, P. L. (2003). Results of milk samples submitted for microbiological examination in Wisconsin from 1994 to 2001. Journal of dairy science, 86(11), 34663472.

11. Erskine, R. J., Eberhart, R. J., Hutchinson, L. J., Spencer, S. B., \& Campbell, M. A. (1988). Incidence and types of clinical mastitis in dairy herds with high and low somatic cell counts. Journal of the American Veterinary Medical Association, 192(6), 761-765.

12. Ng-Kwai-Hang, K. F., Hayes, J. F., Moxley, J. E., \& Monardes, H. G. (1984). Variability of test-day milk production and composition and relation of somatic cell counts with yield and compositional changes of bovine milk. Journal of Dairy Science, 67(2), 361-366. 